\title{
Change Point and Degree Day Baseline Regression Models in Industrial Facilities
}

\author{
Allyson Golden, Keith Woodbury, Joseph Carpenter ${ }^{1}$, Zheng O’Neill \\ Department of Mechanical Engineering, University of Alabama, Tuscaloosa, AL 35487
}

\begin{abstract}
Industrial facilities account for 33\% of the annual energy usage within the United States [17] and this large sector of the domestic energy budget presents significant opportunities for energy efficiency. In order to effectively analyze energy savings opportunities in industrial facilities, adequate baseline models of energy usage in the facilities are needed. Multiple methods of creating baseline energy models have been used in commercial and residential buildings, however, few of these techniques have been made applied to develop baseline energy models in industrial facilities.

The paper investigates the application of standard regression models used for commercial and residential buildings to industrial facilities using sparse energy consumption data. An analysis of the effectiveness of three parameter cooling (3PC) and cooling degree day (CDD) regression models to develop baseline energy usage models in industrial facilities from commonly available utility bill data is presented. Two case studies are investigated: in both case studies a comparison between 3PC model and CDD model is presented. In both cases the baseline regression models meet the recommended NMBE from the ASHRAE Guideline 14. A method to determine process equipment energy usage and cooling end use due to internal loads is presented.
\end{abstract}

Key Words: change-point, cooling degree day, industrial facility energy consumption, regression

\section{Introduction}

Over the past few decades the topic of energy has become prominent in the sciences, politics, and the

\footnotetext{
${ }^{1}$ Corresponding Author: Email: jcarpenter@crimson.ua.edu
}

(C) 2017. This manuscript version is made available under the Elsevier user license http://www.elsevier.com/open-access/userlicense/1.0/ 
media. Understanding energy usage and increasing end-use energy efficiency of existing residential, commercial and industrial facilities is one of the important solutions to the problem of rapidly-growing worldwide energy demand. While both residential and commercial buildings have been extensively analyzed [1-13], industrial buildings have enjoyed minimal investigations [14-16]. Industrial facilities account for 33\% of the annual energy usage within the United States [17], and increasing industrial buildings' energy efficiency by at least $20 \%$ over the next 10 years is the primary goal of the US Department of Energy's "Better Buildings, Better Plants Program" [18]. The U.S. House Committee on Appropriation stated that "Energy costs are a major contributor to manufacturing costs and technology innovations that steeply reduce energy consumption in industrial and manufacturing processes can give American manufacturers competitive advantages in the global marketplace" [19]. Industrial facilities need to be analyzed to understand energy usage within the facility and to identify energy saving opportunities. Developing suitable baseline energy models is essential to understanding current energy use and exploring energy-saving alternatives.

Industrial facilities are those that are not residential or commercial buildings. This study considers industrial facilities that are small or medium sized manufacturing facilities (e.g., foundries, automotive plants, printing facilities, etc.) and not laboratory or data processing facilities. Most industrial facilities do not have sub-metering of individual energy systems and/or components (e.g., air conditioning, lighting, processing equipment, etc.), so the only source of energy consumption data commonly available is the monthly utility bills. The highest energy consumption in a manufacturing facility is related to manufacturing processes, followed by the heating, ventilation, and air-conditioning (HVAC) system [2021]. For example, in automobile assembly facilities the HVAC system consumes up to $36 \%$ of electricity [20]. Therefore, the combined energy demand of the production and HVAC systems largely determines the total energy cost. Even facilities that are not conditioned year round will have equipment that is weather dependent (e.g., chillers for process cooling, cooling towers for foundries, etc.). In our study, the baseline energy estimation is for both building mechanical and energy system related (e.g. HVAC and 
lighting) and production process. Sonderegger [22] shows that accurate baseline energy models can be created using utility data provided by a facilities utility provider.

In order to understand the energy consuming behavior of any building or facility, a baseline energy model must be established. Baseline energy models are created to provide a reference on energy usage for future prediction or energy management. Figure 1 displays the basic concept for creating a baseline model as defined by ASHRAE Guideline 14 [23]. While baseline energy models are generally used for determining energy savings after implementing energy conservation measure (ECM), a baseline energy model provides other useful data as well. Baseline energy models can help characterize end-user consumption, identify energy saving retrofit projects and estimate the savings potentials of those proposed projects, and calculate actual energy savings of retrofit projects after implementations. In industrial facilities, a baseline energy model also shows if energy is mostly being used for production or other applications (e.g., facility lighting, heating and cooling, etc.). With this knowledge an industrial facility is better able to determine the best ways to reduce energy in their facility Thus, it will reduce overall manufacturing cost, which will make products more competitive.

Baseline energy methods presented in the established literature are separated by two commonly used basic ideas: forward models, and inverse models [1-2]. Forward models, like calibrated building simulations, are intended to solve the "forward problem." That is, forward models are better suited for designers concerned with calculating the peak and average loads on a building based on the design inputs. However, the inverse model, like data-driven regression analysis, may alternatively be used to solve the "inverse problem." That is, one can learn about the building or facility characteristics by determining a baseline energy consumption model based on observed and/or measured energy use, obtained from utility bills and/or any energy management system. In industrial facilities a baseline regression model can also disaggregate the total usage into production-dependent energy usage, weather-dependent energy usage, and independent weather usage[14]. This information is then useful in determining end-user energy usage. Therefore, the objective of this investigation is to examine the effectiveness of simple inverse 
linear statistical regression models for establishing baseline energy consumption models for industrial manufacturing facilities, while also using these models for disaggregation of energy dependency on production, weather, and independence from both. This study also presents using regression parameters to help determine energy usage by end-users in a facility.

\section{Literature Review}

Calibrated simulation models constitute another category of methods for creating baseline energy use models. These models replicate the characteristics of a building and the energy consuming equipment within the building. Users of these models are often concerned with the "forward problem," as specified by Rabl et al. [1]; they have the description and characteristics of the building in the design phase, and want to calculate the average and peak energy consumption loads. The software for calibrated building simulation model can range from sophisticated whole building modeling, such as DOE-2 [24], eQuest [25], and EnergyPlus [26], to simplified HVAC-concentrated modeling, such as ESim [27]. Not only have calibrated simulation models been used to create baseline energy models of buildings [3], but they have also been used to measure energy savings between pre- and post-retrofit periods [4-5]. Due to calibrated building simulation or forward analysis requiring highly detailed models that are difficult to obtain in industrial facilities, this type of modeling is very time dependent and not relatively useful for the time required to make and calibrate these models.

Change-point models are piecewise linear regression models, which combine two or more linear regressions [28]. They are also referred to as first order spline models, which provide superior approximation in comparison to low-order polynomial expressions for functions that have local, abrupt changes [29]. Change-point models that use linear and non-linear regression analysis are the preferred method of ordinary least squares regression analysis when creating a baseline energy model. Most regression models have been found to be linear and of the first order due to the thermodynamic principles of energy flow in buildings and the simplicity of the statistics involving the formulation of the linear models [6]. These types of models have been commonly used in both commercial and residential analysis 
Change-point regression models have been used to understand energy usage in industrial facilities [14] and to measure energy saving in industrial facilities [15-16]. Kissock and Seryak [14] used a threeparameter multivariate cooling model (3PC-MVR) analysis to breakdown energy use between production-dependent, weather-dependent, and weather-independent and production-independent. They were able to predict plant-wide natural gas use with a CV-RMSE of less than 6\%. Sever, et al. [15] used change point models to measure energy saving in industrial facilities by developing a pre-retrofit 3PCMVR model and a post-retrofit 3PC-MVR using actual weather data. The energy savings was then computed using typical meteorological year data (TMY) and comparing the total energy usage generated by the pre-retrofit model to the energy usage of the post retro-fit model. Kissock and Eger [16] broke down energy savings in industrial facilities using a 3PC-MVR. They compared the savings calculated by the 3PC-MVR to predicted energy savings estimated by the Dayton Industrial Assessment Center.

The objective of this investigation is to examine the effectiveness of simple inverse linear statistical regression models for establishing baseline energy consumption models for industrial manufacturing facilities, and to use these models to disaggregate energy consumption into dependence on production, weather, or independence from both. Extensive research using regression analysis or calibrated building simulations has been performed in order to create baseline energy consumption models for residential buildings and commercial institutions [2, 7-10, 11-13]. However, few attempts have been made to discuss the applicability of these methodologies to generate baseline energy consumption models for industrial manufacturing facilities [14-16]. In all cases for industrial facilities only 3PC-MVR models were used. It follows that there is a need in the established literature to discuss the methodologies and to determine their applicability for determining baseline energy consumption models of industrial manufacturing facilities. Without appropriate baselining methodologies, or poor model fits, baseline energy models have no predictive ability or relevant applications to the energy consumption behavior of an industrial manufacturing facility. 


\section{Methodology}

This section discusses the different regression models used in this paper. Three different regression models will be analyzed in this study: three-parameter cooling (3PC), cooling degree-day (CDD), and three-parameter multivariate cooling (3PC-MVR). Each model will be described with background information given and the final equation and parameters described. For all models the energy usage is calculated per day.

\subsection{Three-Parameter Cooling (3PC) Models}

As suggested by the name, the three-parameter cooling change-point model (3PC) employs three regression parameters: the constant weather-independent energy consumption, the weather-dependent cooling or heating slope, and the cooling or heating balance or change-point temperature. Typically, 3PC models display electrical energy use utilized for cooling and other electrical end users. Many published resources have presented the validity of the three-parameter cooling and three-parameter heating models when evaluating the baseline energy consumption in residential, commercial and some industrial settings. In fact, Sever et al. [15] suggested that the weather dependence of energy consumption may be accurately described by three-parameter change-point models for most industrial facilities. Figure 2 shows the graphical representation of the 3PC change-point model. In 3PC models, energy use remains constant up to the balance-point temperature, at which energy use begins to linearly increase with rising outside ambient temperature. Eq. (0) summarizes the formula for a three-parameter cooling change-point model [8]. In Eq. (0), $\beta_{1}$ is the constant weather-independent variable and $\beta_{2}$ is the weather-dependent slope term. $T_{b, c}$ is the temperature change-point. $T_{b, c}$ is the outdoor temperature at which cooling is required. $T_{a m b}$ is the facility's ambient temperature. The "+" sign following the brackets represents that only the positive temperature differences are evaluated, otherwise the difference is equal to zero.

$$
E=\beta_{1}+\beta_{2}\left(T_{a m b}-T_{b, c}\right)^{+}
$$




\subsection{Cooling Degree-Day (CDD) Models}

Similar to the 3PC change-point model, the variable-base cooling degree-day (CDD) model provides three physical parameters: the weather or temperature-independent energy use, the weather-dependent cooling slope, and the cooling balance-point temperature. Energy consumption is computed using the number of cooling degree-days required by the facility based on the specified cooling balance-point temperature. Typically, CDD models represent electrical energy used for cooling and other electrical end users. A graphical representation of the cooling degree-day model is shown in Figure 3.

Cooling degree-days may be first defined as the sum of the temperature differences between the average daily ambient dry-bulb temperature and the indoor cooling set-point temperature of a facility over a given time interval, $i$, over a period of $N_{i}$ days. In other words, it is a measure of how much and how long the outdoor air temperature was above a specified reference temperature. The equation for cooling degreedays as a function of the interior cooling set-point temperature is represented in Eq. (0) [8]. In Eq. (0) CDD is the number of cooling degree days over a specified time interval as a function of $T_{b, c}$. In this equation $N$ is the total number of day in the specified time interval and $T_{a m b, i j}$ is the average outdoor air temperature for the $j^{\text {th }}$ day of the time interval. Similar to the 3PC model, the "+" sign following the brackets represents that only the positive temperature differences are evaluated, otherwise the difference is equal to zero.

$$
C D D_{i}\left(T_{b, c}\right)=\sum_{j=1}^{N_{i}}\left(T_{a m b, i j}-T_{b, c}\right)^{+}
$$

Cooling degree-day inverse models have the ability to utilize hourly, daily, or monthly data. The time interval of data represented in the regression model is often determined by the type of data available from the facility. Most industrial facilities track energy through the analysis of monthly utility bills. The number of days in each month, and thus the number of days observed during each utility bill service period, varies throughout the year. Eq. (0) shows the formula for the variable-base cooling degree-day 
model, similar to the linear model presented by Fels [8] $\beta_{I}$ is the base level energy consumption or the weather-independent variable. $\beta_{3}$ may be used to define the quotient between the heat loss coefficient and the cooling coefficient of performance [15]. This means that $\beta_{3}$ is defined as the weather-dependent slope. $\mathrm{CDD}_{\mathrm{i}, \text { bar }}$ is the average numbers of degree days per day for each month.

$$
E=\beta_{1}+\beta_{3}\left[\overline{C D D_{i}}\left(T_{b, c}\right)\right]
$$

It is important to note that the number of cooling degree-days based upon the balance point temperature is the single independent variable in the CDD energy equation. Furthermore, the number of cooling degreedays is directly dependent upon the cooling balance-point reference temperature.

An attractive feature of the CDD model is its close relationship to accepted physical models for building energy usage. Conductive heat gain through a building envelope can be computed for quasi-steady conditions using Eq.(0). In Eq. (0) $T_{i}$, represents the temperature within the facility and $R_{t h}$ is the thermal resistance through the building envelope. Also beneficial from the CDD model is the sensible heat gain from infiltration and ventilation can be computed using Eq. (0). In Eq. (0), $m_{\text {dot }}$ is the mass flow rate of infiltration air and $c_{p}$, is the specific heat of air. Based on Eqs. (0) and (0) the conductive heat gain and infiltration heat gain can be determined based on the amount of CDDs.

$$
\begin{gathered}
\dot{Q}_{\substack{\text { cond } \\
\text { annual }}}=\int_{\text {year }} \frac{T_{\text {amb }}(t)-T_{i}}{R_{\text {th }}} d t=\frac{1}{R_{\text {th }}}\left(\int_{\text {year }} T_{\text {amb }}(t)-T_{i}\right) d t=\frac{C D D}{R_{t h}} \\
\dot{Q}_{\substack{\text { inf } \\
\text { annual }}}=\int_{\text {year }}\left(\dot{m} c_{p}\right)\left(T_{\text {amb }}(t)-T_{i}\right) d t=\dot{m} c_{p} \int_{\text {year }}\left(T_{\text {amb }}(t)-T_{i}\right) d t=\dot{m} c_{p} \times C D D
\end{gathered}
$$

\section{Measures of Goodness}

The goodness-of-fit of a statistical model helps describe the discrepancy between observed values and values calculated by the statistical model. Goodness-of-fit can also determine how well a statistical model will predict a future set of observations. There are multiple methods for determining a model's goodness- 
of-fit in statistical analysis; however, no general guidelines exist for selecting an appropriate goodness-offit method. For this analysis, the coefficient of determination, $\mathrm{R}^{2}$, the coefficient of variation of the root mean square error, CV-RMSE, and the normalized mean bias error, NMBE, were used to determine goodness-of-fit and model strength.

The coefficient of determination, $R^{2}$, displayed in Eq. (0), quantifies the proportion of variation of the measured data that is explained by the regression model. In Eq. (0) $y_{a c t}$ is the actual energy usage per month for the plant, while $y_{\text {mod }}$ is the calculated energy usage per month. Also in Eq. (0), $\bar{y}_{\text {avg }}$ is the average energy usage per facility. It is the population proportion of variability in the dependent variable that is accounted for by the best liner combination of predictors [30]. $R^{2}$ is a value between zero and one, with an $R^{2}$ value equal to one indicating a perfect fit between the measured data and the regression model. An $R^{2}$ value of zero indicates that the regression model provides no better fit than the mean of the measured data [7]. The closer the $R^{2}$ value is to one, the closer the regression model is to predicting the behavior of the dependent variable.

$$
R^{2}=1-\frac{\sum\left(y_{a c t}-y_{\mathrm{mod}}\right)^{2}}{\sum\left(y_{a c t}-\bar{y}_{\text {avg }}\right)^{2}}
$$

The root mean square error, RMSE, is a measure of the scatter or deviation of the measured data around the regression model as shown in Eq. (0). In Eq. (0) $y_{a c t}$ and $y_{m o d}$ are the actual facility energy usage per month and model-predicted energy usage per month respectively. Also in Eq. (0) $n$ represents the number of observed values and $p$ represents the number of regression parameters used in the analysis.

$$
R M S E=\sqrt{\frac{\sum\left(y_{a c t}-y_{\bmod }\right)^{2}}{n-p}}
$$

The CV-RMSE is the ratio of the root mean variation of the dependent variable that is not explained by the regression model and the mean value of the observed data, as displayed is Eq. (0). CV-RMSE values 
are provided as percentages. The smaller the CV-RMSE value the better goodness-of-fit for the regression model.

$$
C V-R M S E=\frac{R M S E}{\bar{y}_{a v g}}
$$

The NMBE is the ratio of the difference between actual energy usage and model predicted energy usage to the degrees of freedom and average energy usage by the facility and is displayed in the Eq. (0). Similar to the CV-RMSE values smaller NMBE values mean a better goodness-of-fit for the regression model.

$$
N M B E=\frac{\sum\left(y_{a c t}-y_{\text {mod }}\right)}{(n-p) \times \bar{y}_{\text {avg }}} \times 100
$$

For the case studies presented below a $\mathrm{R}^{2}$ value of 0.75 as a "good-fit" [22]. Table 1 shows the ASHRAE Guideline 14 recommended values for CV-RMSE and NMBE for baseline energy models [23]. In the analyses in this paper, which utilize monthly utility bill data, the suggestion from Reddy et al. [31] that a CV-RMSE of $5 \%$ or less is an excellent model fit, $10 \%$ or less is a good model, and $15 \%$ or less is a mediocre model fit will be followed.

\section{Disaggregation of Energy Usage}

This section presents the equations used for disaggregation of the model predicted energy usage and the disaggregation of the facility's energy usage. Disaggregation of model components into production, weather, and independent components has been presented in several papers $[14,33]$. The models have also been used to disaggregate energy savings [16]._Then parameters of the models are presented in terms of facility energy usage and building structure.

\subsection{Model Disaggregation}

The weather and production independent portion of the annual energy consumption is calculated by multiplying the independent energy variable $\beta_{1}$ by the number of days in a year as displayed in Eq. (0). 
This equation estimates the amount of energy used by the plant regardless of production or temperature.

$$
I D(T)=\beta_{1} \times 365
$$

The weather dependent portion for the 3PC and 3PC-MVR models is calculated by multiplying the weather dependent variable $\beta_{2}$ by the summation of number of days per month $N_{i}$ times the difference between average ambient temperature $T_{i}$ and change-point temperature $T_{C P}$ from the regression analysis as shown in Eq. (0).

$$
W D(T)=\beta_{2} \times \sum_{i=1}^{12}\left[N_{i} \times\left(T_{i}-T_{C P}\right)^{+}\right]
$$

The weather dependent portion of the CDD model can be calculated by multiplying the weatherdependent variable $\beta_{2}$ by the summation of number of days per month $N_{i}$ times the average number of degree days found from the regression analysis as shown in Eq. (0).

$$
W D(T)=\beta_{2} \times \sum_{i=1}^{12}\left[N_{i} \times \overline{C D D_{i}}\left(T_{b, c}\right)\right]
$$

The percentage of independent, production and dependent usage is found by dividing each by the total energy usage estimated by the model.

\subsection{Facility Energy Usage Disaggregation}

Disaggregating facility energy usage is important because it allows the facility to understand the portion of energy going to different components and the amount that is actually being used for production. Abels et al. [33] presents further details on the importance of disaggregation.

Facility energy usage can also be disaggregated into several different end use components; lighting, HVAC, and process equipment being the main components in industrial facilities. The lighting component can easily be estimated with an extensive light count done in the facility walk through. The estimation of energy usage by the equipment and HVAC components can be more challenging because 
estimating the usage and loads of equipment and air conditioning is difficult to determine without submetering. Eq. (0) shows the disaggregation of a facility's total energy usage into the major energy end use components. The usage of change-point and degree day models can help determine the value of the different energy end use components in Eq. (0).

$$
E U=\left(E_{\text {lights }}+E_{H V A C}+E_{\text {equip }}\right) O H
$$

HVAC energy usage, $E_{H V A C}$, is a response to internal loads and ambient weather conditions for maintaining a design indoor environment condition. In an industrial facility, either of these components can be the main contributor for the total energy usage. Eq. (0) shows the breakdown of $\mathrm{E}_{\mathrm{HVAC}}$ into the internal heat gains, the infiltration, and the heat transfer through the building envelope. The internal heat gains that can contribute to HVAC cooling load include: heat from the lights, heat from indoor equipment which is a fraction of the total equipment energy usage, and heat produced by the occupants. Eq. (0) shows the formula for internal heat gains on the HVAC load. Inserting Eq. (0) into Eq. (0) yields Eq. (0). By regrouping Eq. (16) the internal cooling load and weather dependent cooling load is separated as shown in Eq. (17). Eq. (18) shows the HVAC load due to internal heat gains while Eq. (19) shows the A/C load due to the ambient weather. Using Eqs. (18) and (19) Eq. (17) is rewritten as shown in Eq. (20).

$$
\begin{gathered}
E_{H V A C}=\left(\dot{Q}_{\text {int }}+\left[U A+\dot{m}_{o} c_{p}\right]\left(T_{\text {out }}-T_{\text {in }}\right)\right) \frac{1}{C O P} \\
\dot{Q}_{\text {int }}=f E_{\text {equip }}+E_{\text {lights }}+\dot{Q}_{\text {occ }} \\
E_{H V A C}=\left(f E_{\text {equip }}+E_{\text {lights }}+\dot{Q}_{\text {occ }}+\left[U A+\dot{m}_{o} c_{p}\right]\left(T_{\text {out }}-T_{\text {in }}\right)\right) \frac{1}{C O P} \\
E_{H V A C}=\frac{f E_{\text {equip }}+E_{\text {lights }}+\dot{Q}_{\text {occ }}+\left[U A+\dot{m}_{o} c_{p}\right]\left(T_{\text {out }}-T_{\text {in }}\right)}{C O P} \\
C O P \\
E_{H V A C \text {,int }}=\frac{f E_{\text {equip }}+E_{\text {lights }}+\dot{Q}_{\text {occ }}}{C O P}
\end{gathered}
$$




$$
\begin{aligned}
E_{H V A C, W D} & =\frac{\left[U A+\dot{m}_{o} c_{p}\right]\left(T_{o u t}-T_{\text {in }}\right)}{C O P} \\
E_{H V A C} & =E_{H V A C, \text { int }}+E_{H V A C, W D}
\end{aligned}
$$

Applying Eq. (0) to Eq. (0) and regrouping into cooling independent terms and cooling dependent terms yields Eq. (4). Eq. (4) can then be separated into cooling dependent components and cooling independent components as shown in Eq. (4).

$$
\begin{gathered}
E U=\left(\left[E_{\text {lights }}+E_{\text {equip }}\right]+\left[\left(f E_{\text {equip }}+E_{\text {lights }}+\dot{Q}_{\text {occ }}+\left[U A+\dot{m}_{o} c_{p}\right]\left(T_{\text {out }}-T_{\text {in }}\right)\right) \frac{1}{C O P}\right]\right) O H \\
E U=\left(E_{\text {ind }}+E_{\text {cooling }}\right) O H
\end{gathered}
$$

Ideal equipment energy usage would vary directly with plant production but inevitably there is some base level energy usage associated with zero production (to maintain equipment and when idle). The energy usage of plant equipment can be broken down into the components shown in Eq. (4).

$$
E_{\text {equip }}=E_{\text {equip }, 0}+E_{P} P_{\text {tot }}
$$

Plugging Eq. (4) into Eq. (4) allows the energy usage of components to be related to the parameters of the change-point and degree day models. Eq. (4) shows the final version of the component breakdown of energy usage in a facility. Occupancy effect on the cooling load is assumed to be relatively small compared to effects from lighting, equipment and building envelope, therefore heat gains from occupants is left out of the equation.

$$
E U=\left(\begin{array}{l}
{\left[E_{\text {lights }}+E_{\text {equip }, 0}+E_{P} P_{\text {tot }}\right]+} \\
{\left[\left(f\left(E_{\text {equip }, 0}+E_{P} P_{\text {tot }}\right)+E_{\text {lights }}+\left[U A+\dot{m}_{o} c_{p}\right]\left(T_{\text {out }}-T_{\text {in }}\right)\right) \frac{1}{C O P}\right]}
\end{array}\right) O H
$$




\subsection{Facility Energy Usage Related to Model Parameters}

The facility energy usage components are relatable to three of the parameters of the degree day and change-point multivariable models. The $\beta_{1}$ parameter relation to facility usage is shown in Eq. (4), while

the $\beta_{4}$ parameter of the multivariable models is shown in Eq. (4). When using the basic degree day and change-point models the $\beta_{4}$ parameter is lumped into the $\beta_{1}$ parameter.

$$
\begin{gathered}
\beta_{1}=\left(1+\frac{f}{C O P}\right)\left(E_{\text {equip }, 0}+E_{P} P_{\text {tot }}\right)+\left(1+\frac{1}{C O P}\right) E_{\text {lights }} \\
\beta_{4}=\left(1+\frac{f}{C O P}\right) P_{\text {tot }}
\end{gathered}
$$

Sever et al. [15] propose that the infiltration and building envelope information can be found using $\beta_{2}$ of the change-point and degree day model as shown in Eq. (4). In this study, the slope of the degree day model is also related to the building envelope and infiltration as shown in Eq. (4).

$$
\beta_{2}=\frac{U A+\dot{m} c_{p}}{C O P}=\beta_{3}
$$

The change-point temperature, $\mathrm{T}_{\mathrm{b}, \mathrm{c}}$, of both models is helpful in estimating the $\mathrm{E}_{\mathrm{A} / \mathrm{C}}$ usage in a facility as shown in Eq (28). $\mathrm{T}_{\mathrm{b}, \mathrm{c}}$, is used to determine the number of cooling hours, $\mathrm{CH}$, in a facility using the bin method. In Eq. (28) Tons, is the size of the A/C units and LF is a comparison of the actual load on the unit to running fully loaded. Eq. (28) is used to calculate the energy usage for each unit within a facility since different units will be various sizes, with different efficiencies, and different loads. The load factor, $\mathrm{LF}$, for each $\mathrm{A} / \mathrm{C}$ unit is estimated to ensure the total energy usage for all the $\mathrm{A} / \mathrm{C}$ units in a facility is similar to the total HVAC energy usage found from either the 3PC model or the CDD model.

$$
E_{A / C}=\frac{T o n s}{C O P} \times C H \times L F
$$




\section{Case Studies}

This section presents a background on Industrial Assessment Centers (IAC) and two case studies. The first case will present a comparison between 3PC regression models, 3PC-MVR regression models, and CDD regression models. The second case will compare 3PC regression models with CDD regression models. Due to the lack of a reliable database of historical weather data, in all cases TMY3 [32] data was used for ambient temperature values.

\subsection{IAC Background}

Each case study presented utilizes data obtained by the Alabama Industrial Assessment Center (AIAC). The names of individual companies are withheld due to confidentiality but, facility location, manufactured product, and basic information are provided.

The AIAC is one of twenty-four centers sponsored by the Department of Energy's Energy Efficiency and Renewable Energy [1] division. The IACs assist manufacturers and industrial facilities with energy conservation, waste reduction, and productivity enhancement. Standard IAC protocol requires analysis of a 12-month history of facility utility bills. Thus, AIAC has annual energy usage for all facilities it has serviced (over 170 facilities as of November 2016). From this broad database, two clients are anonymously selected for case studies in this investigation.

\subsection{Case Study 1:}

Facility A is an industrial manufacturing facility located in east Alabama. The facility covers a total of 130,000 square feet, and is enclosed in one large building structure. The facility includes the main production area and office spaces and uses electricity to supply energy to air conditioning units (for space cooling), lighting, air compressors, and process equipment. A large number of grinders, drill presses, and hydraulic rod benders are used to make parts. The facility operates 24 hours per day, 5 days per week, 50 weeks each year. The entire facility is conditioned year-round by over 800 tons of air conditioning so it is assumed that the facility's energy consumption varies with outdoor temperature. Facility personnel 
provided electric bills. During the plant visit IAC personnel performed an extensive light count to determine lighting electrical usage. During the week following the visit amperage draw on the facilities air compressors was recorded then used to determine the energy usage by the air compressors for the year. This case study will examine the use of 3PC and CDD models to establish baseline energy models for the facility's electrical energy use.

A 3PC change-point model was analyzed for the facility. Following the regression analysis using the Excel Solver feature [34] the final regression parameters for $\beta_{1}, \beta_{2}$, and $T_{b, c}$ are $13,960 \mathrm{kWh} / \mathrm{day}$, $337 \mathrm{kWh} /$ day- ${ }^{\circ} \mathrm{F}$, and $5.0^{\circ} \mathrm{C}$, respectively. The 3PC change-point model is shown in Eq. (5). The $R^{2}$ value for Eq. (5) is 0.534 , the $C V-R M S E$ is $14.9 \%$, and the $N M B E$ is -0.169 . Although the $R^{2}$ value indicates a poor relationship between ambient temperature and facility energy usage, the CV-RMSE and NMBE both meet the ASHRAE requirements for goodness of fit.

$$
E=13,960 \frac{k W h}{d a y}+337 \frac{k W h}{d a y \cdot{ }^{\circ} C}\left(T_{a m b}-5.0^{\circ} C\right)^{+}
$$

Figure 4 shows the 3PC change-point model for Facility A. The figure shows that due to a high internal heat load that the facility is cooling almost year round. This can be determined because the change-point temperature is $5{ }^{\circ} \mathrm{C}$ which is below normal temperatures in Alabama even during the winter months. As can be seen in the figure the only month with an average ambient temperature near the change-point temperature is January._Although the data is scattered, the graph does indicate an increase in electrical energy use as ambient dry-bulb temperatures increase. The $3 \mathrm{PC}$ model suggests that $77.0 \%$ is weatherindependent with $23.0 \%$ being weather dependent based upon Eq. (0) and Eq. (0).

A variable-base cooling degree-day (CDD) regression analysis was also performed for Facility A. Following the regression analysis, the final CDD regression parameters for $\beta_{l}, \beta_{3}$, and $T_{b, c}$ are $13,660 \mathrm{kWh} /$ day, $271 \mathrm{kWh} / \mathrm{day}^{2}-{ }^{\circ} \mathrm{C}$, and $0.00^{\circ} \mathrm{C}$, respectively. The CDD baseline energy model for Facility A is shown in Eq. (5). The $R^{2}$ value is 0.244 , the $C V$-RMSE is $19.0 \%$, and the NMBE is -0.080 . The $R^{2}$ value indicates a poor relationship between ambient temperature and energy usage. While the 
$C V$-RMSE value does not meet ASHRAE criteria the $N M B E$ does.

$$
E=13,660 \frac{k W h}{d a y}+271 \frac{k W h}{d a y^{2} \cdot{ }^{\circ} C}\left[\overline{C D D_{i}}\left(0.0^{\circ} C\right)\right]
$$

Figure 5 shows the facility's electrical energy use a function of cooling degree-days as explained by the CDD empirical model. The CDD model indicates that $75.4 \%$ of the total electrical energy use is weatherindependent, and $24.6 \%$ of the total electrical energy use is weather-dependent.

Figure 6 illustrates the actual monthly energy usage, the monthly energy usage as modeled by the 3PC change-point regression, and the monthly energy usage as modeled by the CDD regression. A plot of energy versus time of year is a good starting point for evaluating industrial facility energy use. It shows whether ambient temperature is a significant factor [1]. If the simple time plot shows that energy consumption is not weather-dependent, the relationship can be ruled out and other independent variables, such as production, may be analyzed.

Figure 6 shows that the electrical energy use varies throughout the year. The electrical energy consumption slightly increases during some of the summer months and from May to August the energy usage increases with a near constant slope. One of the main reasons the goodness of fit values is indicate poor fits is due to the high electrical energy consumption by the plant in September and October. This could be due production but facility personnel were unable to provide detailed production data. Table 2 displays the $\mathrm{R}^{2}, \mathrm{CV}-\mathrm{RMSE}$, and NMBE values for the three models. The 3PC model had better $\mathrm{R}^{2}$ and CV-RMSE numbers while the CDD model provided a better NMBE value. Only the 3PC model meet ASHRAE Guideline 14 standards for a baseline model using CV-RMSE and NMBE values.

After completing the regression model, the 3PC model was used to help determine the total motor horsepower in the facility. During the visit IAC personnel noticed that the facility had a large number of smaller motors but were unable to acquire an extensive number count due to the number and type of machinery used. Personnel also observed that half of the compressors were located within the conditioned 
space. IAC personnel were able to acquire the coefficient of performance (COP) of the air conditioners and a weighted average is used in this calculation. The $\beta_{1}$ parameter of the 3PC model was then used to determine the energy usage of the motors each day. Eq. (5) shows the relationship between $\beta_{1}$ and the energy users in the facility. Eq. (5) through Eq. (5) shows algebraic manipulation of Eq. (5) to solve the $E_{\text {equip. }}$ The value determined for $E_{\text {equip }}$ may not be entirely for motors but the assumption was made that a large portion of these value was for process motors.

$$
\begin{gathered}
\beta_{1}=E_{\text {equip }}+E_{\text {lights }}+E_{\text {aircomp }}+\frac{E_{\text {lights }}+E_{\text {motors }}+0.5 \times E_{\text {aircomp }}}{C O P} \\
13,960 \frac{\mathrm{kWh}}{d a y}=E_{\text {equip }}+2,700 \frac{\mathrm{kWh}}{d a y}+2,900 \frac{\mathrm{kWh}}{d a y}+\frac{2,700 \frac{\mathrm{kWh}}{\mathrm{day}}+E_{\text {equip }}+1,450 \frac{\mathrm{kWh}}{\mathrm{day}}}{3.2} \\
\left(1+\frac{1}{3.2}\right) E_{\text {equip }}=7,063 \frac{\mathrm{kWh}}{\mathrm{day}} \\
E_{\text {equip }}=5,381 \frac{\mathrm{kWh}}{\mathrm{day}}
\end{gathered}
$$

After performing the regression analysis, a good estimation of the energy usage by end use (i.e. HVAC, lighting, motors, air compressors, etc.) can be determined and presented to the facility management team. Multiplying the energy usage for equipment shown in Eq. (5) by the number of days in a year and dividing by the total energy usage of the facility, process motors account for $30 \%$ of the energy usage in the facility. After determining the daily energy usage used by process equipment the HVAC portion of the independent energy usage was calculated based upon (2). The internal and weather dependent parts of the HVAC energy usage were then added together before being divided by the overall energy usage in the facility. The analysis showed that $39 \%$ of the energy in the facility was for space cooling. Determining the energy usage by motors also allowed detailed calculation for ECMs specifically to motors. Such calculations will make the recommended ECM more actionable. 


\subsection{Case Study 2:}

Facility B is an industrial manufacturing facility located in west Alabama. The facility uses electricity to supply energy for laser welding, motors, compressed air, lighting, space cooling, and other manufacturing processes. The building is approximately 230,000 square feet. To compensate for a high internal heat load, the production floor and office areas are cooled year-round with over 250 tons of air conditioning. Thus, it is expected that the facility's electrical energy consumption will vary with outdoor ambient drybulb temperature. The facility operates 10 hours per day, five days per week, for 49 weeks each year. Electricity is not used for space heating at the facility. This case study examines the use of threeparameter cooling change-point and variable-base cooling degree-day regression methods to establish baseline energy models for the facility's electrical energy use.

A three-parameter cooling change-point regression analysis was performed for Facility B. Electrical service dates for this facility range from the beginning of one month to the beginning of the next calendar month. After the regression analysis was completed, the final regression parameters are as follows: $\beta_{1}=19,524 \mathrm{kWh} /$ day, $\beta_{2}=284 \mathrm{kWh} /$ day $-{ }^{\circ} \mathrm{C}, T_{b, c}=0.0^{\circ} \mathrm{C}$. The $3 \mathrm{PC}$ change-point baseline energy model for Facility B is shown in Eq. (5) The $R^{2}$ value is 0.602 , the $C V$-RMSE is $8.00 \%$, and the NMBE is -0.109 . This suggests that ambient dry-bulb temperature is a moderately influential variable and that the $3 \mathrm{PC}$ change-point model is a good baseline energy consumption model for Facility B.

$$
E=19,524 \frac{k W h}{d a y}+284 \frac{k W h}{d a y \cdot{ }^{\circ} \mathrm{C}}\left(T_{a m b}-0.0^{\circ} \mathrm{C}\right)^{+}
$$

Figure 7 shows the 3PC change-point model for Facility B along with actual monthly energy usage data points. The appropriateness of the regression model Eq. (5) for this plant can be seen in Figure 7, as the high internal load demands a constant contribution to cooling year round and the balance temperature is below the average monthly temperature normally encountered by the facility. The 3PC model indicates that $79.9 \%$ of the total electrical energy use is weather-independent, and $20.1 \%$ of the total electrical energy use is weather-dependent. 
A variable-base cooling degree-day (CDD) regression analysis was also performed for Facility $\mathrm{B}$. Following the regression analysis, the final CDD regression parameters for $\beta_{1}, \beta_{3}$, and $T_{b, c}$ are 20,206 kWh/day, $305 \mathrm{kWh} / \mathrm{day}^{2}-{ }^{\circ} \mathrm{C}$, and $3.8^{\circ} \mathrm{C}$, respectively. The CDD baseline energy model for Facility B is shown in Eq. (5). The $R^{2}$ value is 0.606 , the $C V$-RMSE is $7.96 \%$, and the NMBE is -0.116 . These goodness-of-fit values indicate that ambient temperature is a moderately influential variable and that the CDD change-point model is also a good baseline energy consumption model for this facility.

$$
E=20,206 \frac{k W h}{d a y}+305 \frac{k W h}{d a y^{2} \cdot{ }^{\circ} C}\left[\overline{C D D_{i}}\left(3.8^{\circ} \mathrm{C}\right)\right]
$$

Figure 8 shows the facility's electrical energy use a function of cooling degree-days as explained by the CDD empirical model. The CDD model indicates that $82.7 \%$ of the total electrical energy use is weatherindependent, and $17.3 \%$ of the total electrical energy use is weather-dependent. From Figure 8 , the facility has cooling degree days year round, and the significant increase in cooling demand due to higher degree days is clear for the summer and mid-season months.

Figure 9 illustrates the actual monthly energy use and the monthly energy use as depicted by the 3PC and CDD regression models. The graph shows that the CDD and 3PC models predictions are nearly identical. The 3PC and CDD models have the energy usage for the summer months being almost flat. This is due to the average monthly temperature in the summer being similar. During the winter and fall months, electrical energy use declines at an almost linear rate. Figure 9Error! Reference source not found. indicates that the 3PC baseline energy model sufficiently reflects the weather dependency of Facility B's electricity. Similar to the 3PC model, the CDD sufficiently explains the increase in electrical energy during the summer months as ambient dry-bulb temperatures increase, and the relatively constant energy consumption in the winter and fall months.

The 3PC change-point and CDD regression analyses proved to be sufficient baseline energy consumption models for Facility B. Table 3 displays a comparison of the goodness-of fit for the two models. The CDD model possessed slightly better $\mathrm{R}^{2}$ and CV-RMSE than the 3PC model while the 3PC model possessed a 
slightly better NMBE value. The difference in values for $R^{2}, \mathrm{CV}-\mathrm{RMSE}$, and NMBE were not large enough to provide conclusions as to which model type provides a better fit. The independent energy consumption parameters were similar for both model types but the cooling slope and balance point temperature values for the CDD model were larger than the values for the 3PC change-point model. Furthermore, in comparison to the CDD model the 3PC model indicated that a larger percentage of the total energy use was weather-dependent. Even with slight differences in the models both models gave nearly identical results and both regression models sufficiently indicated the temperature dependency of the electrical energy consumption Facility B.

After completing the regression model, the 3PC model was used to help estimate the cooling required due to internal loads within the facility but both models will be presented for comparison of results. Similar to Case A, an extensive light count was conducted and amperage draw of the compressors were measured for the facility. Half the air compressors in the facility were located within the conditioned space. IAC personnel estimated the energy usage of several chillers within the facility. IAC personnel were able to acquire the coefficient of performance (COP) of the air conditioners and a weighted average is used in this calculation. The $\beta_{1}$ parameter of the $3 \mathrm{PC}$ model was used to determine the energy usage of HVAC system due to internal loads each day. Eq. (5) shows the relationship between $\beta_{1}$ and the energy users in the facility. Eq. (5) through Eq. (5) shows algebraic manipulation of Eq. (5) to solve for $E_{\text {equip. After }}$ determining the equipment load the HVAC energy usage due to internal loads was determined.

$$
\begin{gathered}
\beta_{1}=E_{\text {equip }}+E_{\text {lights }}+E_{\text {aircomp }}+E_{\text {chiller }}+\frac{E_{\text {lights }}+E_{\text {motors }}+E_{\text {aircomp }}}{C O P} \\
19,524 \frac{k W h}{d a y}=E_{\text {equip }}+2,089 \frac{k W h}{d a y}+3,572 \frac{k W h}{d a y}+3,538 \frac{k W h}{d a y}+\frac{2,089 \frac{k W h}{d a y}+E_{\text {equip }}+0.5 \times 3,572 \frac{k W h}{d a y}}{2.5} \\
\left(1+\frac{1}{2.5}\right) E_{\text {equip }}=8,775 \frac{\mathrm{kWh}}{d a y}
\end{gathered}
$$




$$
E_{\text {equip }}=6,268 \frac{\mathrm{kWh}}{\mathrm{day}}
$$

The $\beta_{1}$ parameter of the CDD model was also used to determine the energy usage of the internal equipment each day. Eq. (41) shows the relationship between $\beta_{1}$ and the energy users in the facility. Eq. (6) and Eq. (6) shows algebraic manipulation of Eq. (41) to solve for $E_{\text {equip. }}$. Multiplying the energy usage for equipment shown in Eq. (5) by the number of days in a year and dividing by the total energy usage of the facility, process motors account for $26 \%$ of the energy usage in the facility using the 3PC model. The value determined for $E_{\text {equip }}$ was then used to determine the energy required for cooling due to the internal loads using Eq. (2). The internal and weather dependent parts of the HVAC energy usage were then added together before being divided by the overall energy usage in the facility. The CDD model showed that $35 \%$ of the energy in the facility was for space cooling.

$$
\begin{gathered}
20,206 \frac{k W h}{d a y}=E_{\text {equip }}+2,089 \frac{k W h}{d a y}+3,572 \frac{k W h}{d a y}+3,538 \frac{k W h}{d a y}+\frac{2,089 \frac{k W h}{d a y}+E_{\text {equip }}+0.5 \times 3,572 \frac{\mathrm{kWh}}{d a y}}{2.5} \\
\left(1+\frac{1}{2.5}\right) E_{\text {equip }}=9,457 \frac{\mathrm{kWh}}{\mathrm{day}} \\
E_{\text {equip }}=6,755 \frac{\mathrm{kWh}}{\mathrm{day}}
\end{gathered}
$$

Both models provided similar results for HVAC and equipment energy usage in the facility. Multiplying the energy usage for equipment shown in Eq. (6) by the number of days in a year and dividing by the total energy usage of the facility, process motors account for $26 \%$ of the energy usage in the facility using the 3PC model. After determining the daily energy usage used by process equipment the HVAC portion of the independent energy usage was calculated based upon (2). The internal and weather dependent parts of the HVAC energy usage were then added together before being divided by the overall energy usage in the facility. The 3PC model showed that $37 \%$ of the energy in the facility was for space cooling. The models 
give slightly different energy usages for cooling but are similar that using either model is able to be used for the disaggregation of the facilities energy usage.

\section{Conclusions}

This work analyzed two different regression models for creating baseline energy models for industrial facilities. In both case studies a 3PC change-point regression model was compared to a CDD regression model. For Case 1 only the 3PC model meets both CVRMSE and NMBE recommended by ASHRAE guideline for a baseline model while for Case 2 both models meet the two metrics from ASHRAE guideline. Then in both cases process equipment energy usage and HVAC energy usage in the facilities was estimated using the weather independent portion of the 3PC model. This allowed the energy auditors to have a reasonable estimate on the total horsepower of motors in the facility and HVAC load required for internal heat gains. Overall each of the models meets the NMBE from ASHRAE guideline with none being better than another and the models provides a reasonable estimate of energy usage by process equipment and cooling due to internal heat gains. Future work should include using more data through either a longer time period or a higher sampling frequency during the same time period and a full comparison between baseline disaggregation and industrial facility's sub-metered energy consumption to compare effectiveness of each models disaggregation. Advanced statistical models such as Gaussian Process Regression Model [35-36] and Gaussian Mixture Regression Model [11,37] for baseline energy estimation in industrial facility need to be analyzed. 


\section{References}

[1] Rabl, A., Norford, L., \& Spadaro, J. (1992). Steady State Models for Analysis of Commercial Building Energy Data. ACEEE Summer Study on Energy Efficiency in Buildings, (pp. 9.239-9.261). Pacific Grove, CA.

[2] Zhang, Y., O’Neill, Z., Wagner, T., \& Godfried, A. (2013). An Inverse Model with Uncertainty Quantification to Estimate the Energy Performance of an Office Building. Proceedings of BS2013: $13^{\text {th }}$ Conference of International Building Performance Simulation Association (pp. 614-621). Chambery, France: IBPSA.

[3] Katipamula, S., \& Claridge, D. E. (1992). Monitored Air Handler Performance and Comparison with a Simplified System Model. ASHRAE Transactions, 98(2), 341-351.

[4] Katipamula, S., \& Claridge, D. E. (1993). Use of Simplified System Models to Measure Retrofit Energy Savings. Journal of Solar Energy Engineering: Transactions of the ASME, 115(2), 57-68.

[5] Wilson, J. K. (1998). The Significant Role of Energy Calculations in the Success of Long-Term Energy Guarantees. ASHRAE Transactions, 104(2), 880-894.5, no. 9, pp. 781-798, Dec. 1991.

[6] Haberl, J. S., Reddy, T. A., Claridge, D. E., Turner, W. D., O’Neal, D. L., \& Heffington, W. M. (1996). Measuring Energy-Savings Retrofits: Experiences from the Texas LoanSTAR Program. Springfield: National Technical Information Service, U.S. Department of Commerce.

[7] Kissock, J. K., Haberl, J. S., \& Claridge, D. E. (2003). Inverse Modeling Toolkit: Numerical Algorithms. ASHRAE Transactions-Research, 109(2), (pp. 425-434).

[8]Fels, M. F. (1986). PRISM: An Introduction. Energy and Buildings, 9, 5-18.

[9] Raffio, G., Isambert, O., Mertz, G., Schreier, C., \& Kissock, K. (2007). Targeting Residential Energy Assistance. Proceedings of the Energy Sustainability Conference 2007, 489-496.

[10]Kissock, J.K, Reddy, T.A., \& Claridge, D.E. (1998). Ambient-temperature Regression Analysis for Estimating Retrofit Savings in Commercial Buildings. Journal of Solar Energy Engineering, Transactions of the ASME, 120(3), 168-176.

[11]Zhang, Y., O’Neill, Z., Dong, B., Godfried, A. (2015), Comparisons of Inverse Modeling Approaches for Predicting Building Energy Performance. Building and Environment, 86, 177-190.

[12]Abhishek, S., Ashutosh, T., Dong, B. (2013), Baseline Building Energy Modeling and Loacalized Uncertainty Quantification Using Gaussian Mixture Models. Energy and Buildings, 65, 438-447.

[13]Fei, L., and Pingfang, H. (2009), A Baseline Model for Office Building Energy Consumption in Hot Summer and Cold Winter Region. Proceedings-International Conference on Management and Service Science.

[14]Kissock, J. K., \& Seryak, J. (2004). Understanding Manufacturing Energy Use through Statistical Analysis. Twenty-Sixth Industrial Energy Technology Conference. Houston, TX. 
[15]Sever, F., Kissock, J. K., Brown, D., \& Mulqueen, S. (2011). Estimating Industrial Building Energy Savings using Inverse Simulation. ASHRAE Transactions, 117(1), 348-355.

[16]Kissock, J. K., \& Eger, C. (2008). Measuring Industrial Energy Savings. Applied Energy, 85, 347361.

[17]EIA. February 2015 Monthly Energy Review, US Energy Information Administration (2015). www.eia.gov/mer.

[18]U.S. Department of Energy Office of Energy Efficiency \& Renewable Energy http://energy.gov/eere/amo/better-plants

[19]U.S. House. Committee on Appropriations. Energy and Water Development Appropriations Bill, 2013 (to Accompany H.R. 5325) Together with Additional Views. $112^{\text {th }}$ Congress. 2d Session. Report 112-462. Washington: GPO, 2012. GPO. U.S. Government Printing Office. Web. 2 May 2012. (85). http://www.gpo.gov

[20]Galitsky, C and Ernst, W. (2008) "Energy Efficiency Improvement and Cost Saving Opportunities for the Vehicle Assembly Industry", Ernest Orlando Lawrence Berkeley National Laboratory Report, LBNL-50939-Revision.

[21]U.S. Energy Information Administration Annual Energy Review 2011, DOE/EIA 2012 report, http://www.eia.gov/totalenergy/data/annual/pdf/sec2_14.pdf.

[22]Sonderegger, R. C. (1998). A Baseline Model for Utility Bill Analysis Using Both Weather and Non-Weather Related Variables. ASHRAE Summer Meeting. Toronto.

[23]ASHRAE, ASHRAE Guideline 14: Measurement of Energy and Demand Savings, American Society of Heating, Refrigerating, and Air-Conditioning Engineers, Inc, Atlanta, GA, 2002.

[24] James J. Hirsch \& Associates (JJH), Lawrence Berkeley National Laboratory (LBNL), US Department of Energy (USDOE). (2014). DOE-2 [computer software]. http://doe2.com/DOE2/index.html.

[25] eQuest. (2014). eQuest [computer software]. http://www.doe2.com/equest/.

[26] EnergyPlus. (2013). [computer software]. http://apps1.eere.energy.gov/buildings/energyplus/energyplus_about.cfm.

[27] Kissock, J. K. (2012). Esim [computer software]. http://academic.udayton.edu/kissock/http/RESEARCH/EnergySoftware.htm.

[28]Marsh, L. C., \& Cormier, D. R. (2002). Spline Regression Models. Thousand Oaks: Sage Publications, Inc.

[29]Chapra, S. C. (2008). Applied Numerical Methods with Matlab for Engineers and Scientists (2 ${ }^{\text {nd }}$ ed.). New York, NY: McGraw-Hill.

[30]Chatterjee, S., \& Simonoff, J. S. (2013). Handbook of Regression Analysis. Hoboken, New Jersey: Wiley. 
[31]Reddy, T. A., Saman, N. F., Claridge, D. E., Haberl, J. S., Turner, W. D., \& Chalifoux, A. T. (1997). Baselining Methodology for Facility-Level Monthly Energy Use-Part 2: Application to Eight Army Installations. ASHRAE Transactions, 103(2), pp. 348-359.

[32]U.S. Department of Energy. National Renewable Energy Laboratory, Brief Summary of the TMY3s, 2013, http://www.nrel.gov/rredc.

[33]Abels, B, Sever, F., Kissock, K. \& Ayele, D. (2011) Understanding Industrial Energy Use through Lean Energy Analysis. SAE 2011 World Congress, Detroit, MI, 2011

[34]Golden, A. (2014), Analyzing Industrial Energy Use through Ordinary Least Squares Regression Models. Master Thesis, University of Alabama.

[35] Heo, Y., and Zavala, V.M. (2012). Gaussian Process Modeling for Measurement and Verification of Building Energy Savings. Energy and Buildings, 53, 7-18.

[36]Carpenter, J. Woodbury, K., O’Neill, Z., (2016) A Comparison of Gaussian Process Regression and Change-Point Regression for the Baseline Model in Industrial Facilities. ASHRAE and IBPSA-USA SimBuild 2016, Salt Lake City, UT, 2016

[37]Sung, H.G. (2004). Gaussian Mixture Regression and Classification, Phd Dissertation, Rice University. 


\section{Nomenclature}

E, energy consumption

$\beta_{1}$, independent variable

$\beta_{2}$, weather dependent variable

$\mathrm{T}_{\mathrm{amb}}$, ambient temperature

$T_{b, c}$, change-point temperature

$\operatorname{CDD}()$, cooling degree days

$\mathrm{CDD}_{\text {bar }}$, daily average cooling degree days per month

$\beta_{3}$, cooling degree day weather dependent variable

$Q_{\text {cond,annual, }}$ annual conduction heat transfer

$\mathrm{R}_{\mathrm{th}}$, thermal building resistance

$\mathrm{m}_{\text {dot }}$ mass flow rate

$\mathrm{c}_{\mathrm{p}}$ specific heat

$\mathrm{R}^{2}$, coefficient of determination

$\mathrm{y}_{\text {act}}$, actual monthly energy consumption

$\mathrm{y}_{\text {mod, }}$, model monthly energy consumption

$\mathrm{y}_{\text {avg_bar, }}$ average facility energy consumption

RMSE, root mean square error

$\mathrm{n}$, number of observed values

$\mathrm{p}$, number of regression parameters

CV-RMSE, coefficient of variation of the root mean square error

ID, independent energy consumption

WD, weather dependent energy consumption

$\mathrm{PD}$, production dependent energy consumption

$\mathrm{t}$, time

$\mathrm{T}_{\max }$, maximum temperature

$\mathrm{T}_{\min ,}$ minimum temperature

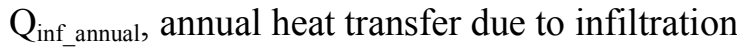

$\mathrm{T}_{\mathrm{i}}$, facility interior temperature

$\beta_{4}$, production dependent variable

$\mathrm{X}_{1}$, production units per month

$\mathrm{P}_{\mathrm{avg}}$, average monthly production

$\mathrm{P}_{\text {tot, }}$, total yearly production

$\mathrm{N}_{\mathrm{i}}$, number of days per month

$\mathrm{D}_{\mathrm{p}}$, total production days

EU, energy usage by facility

$\mathrm{E}_{\text {lights, }}$ energy usage of lights at facility

$\mathrm{E}_{\mathrm{HVAC}}$, energy usage of HVAC system at facility

$\mathrm{E}_{\text {equip }}$, energy usage of process equipment

$\mathrm{OH}$, annual operating hours of facility

$\mathrm{Q}_{\text {dot,internal, }}$ internal heat loads of building

$\mathrm{U}$, average conductive heat transfer coefficient of building

A, surface area of building

$\mathrm{M}_{\mathrm{dot}, 0}$, infiltration of air into building

$\mathrm{T}_{\text {out }}$, ambient air temperature

$\mathrm{T}_{\text {in, }}$, indoor air temperature

$\mathrm{COP}$, coefficient of performance

$\mathrm{Q}_{\text {dotocc }}$,

$E_{\text {ind, }}$, energy usage not related to cooling

$\mathrm{E}_{\text {cooling, }}$ energy usage for cooling

$\mathrm{E}_{\text {equip, }, 0}$, base load energy usage of process

equipment

$E_{P}$, average energy usage per product

$f$, fraction of

Tons, A/C size

LF, load factor 


\section{Superscript}

+only positive values in parenthesis considered, otherwise zero 


\section{List of Tables}

Table 1. Recommended values for baseline model from ASHRAE Guideline 14

Table 2. Comparison of $\mathrm{R}^{2}$, CV-RMSE, and NMBE for both energy models in Case Study 1

Table 3. Comparison of R2, CV-RMSE, and NMBE for both energy models in Case Study 2

\section{List of Figures}

Figure 1. ASHRAE Guideline 14 Basic Method for Determining Savings[ASHRAE (12)].

Figure 2. Three-parameter cooling change-point model (3PC).

Figure 3. Variable-base cooling degree-day model (CDD).

Figure 4 3PC model of monthly electrical energy use for Facility A.

Figure 5 CDD model of monthly electrical energy use for Facility A.

Figure 6 Actual energy usage, 3PC model energy usage, and CDD model energy usage for Facility A.

Figure 7 3PC model of monthly electrical energy use for Facility B.

Figure 8 CDD model of monthly electrical energy use for Facility B.

Figure 9 Actual energy usage, 3PC model energy usage, and CDD model energy usage for Facility B. 
Table 1. Recommended values for baseline model from ASHRAE Guideline 14

\begin{tabular}{ccc}
\hline & Monthly & Hourly \\
\hline CV-RMSE & $15 \%$ & $30 \%$ \\
NMBE & $5 \%$ & $10 \%$ \\
\hline
\end{tabular}

Table 2. Comparison of $\mathrm{R}^{2}$, CV-RMSE, and NMBE for both energy models in Case Study 1

\begin{tabular}{c|ccc} 
Model & $\mathrm{R}^{2}$ & $\mathrm{CV}-$ \\
RMSE & $\mathrm{NMBE}$ \\
\hline CDC & 0.534 & $14.9 \%$ & -0.169 \\
& 0.244 & $19.0 \%$ & -0.080
\end{tabular}

Table 3. Comparison of R2, CV-RMSE, and NMBE for both energy models in Case Study 2

\begin{tabular}{c|ccc} 
Model & $\mathrm{R}^{2}$ & $\mathrm{CV}-$ \\
RMSE & $\mathrm{NMBE}$ \\
\hline CDC & 0.602 & $8.00 \%$ & -0.109 \\
0.606 & $7.96 \%$ & -0.116
\end{tabular}




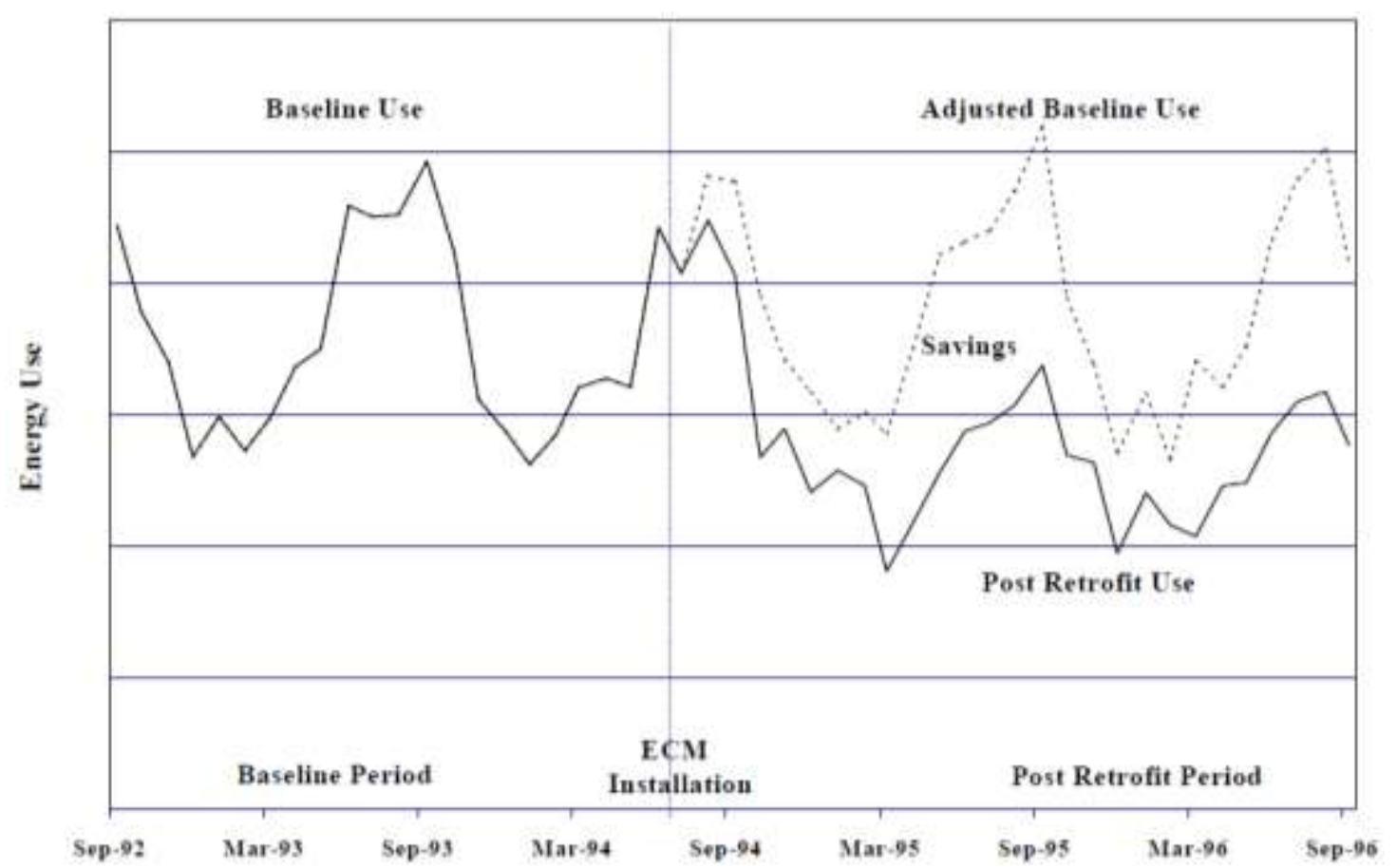

Figure 1. ASHRAE Guideline 14 Basic Method for Determining Savings[ASHRAE (12)].

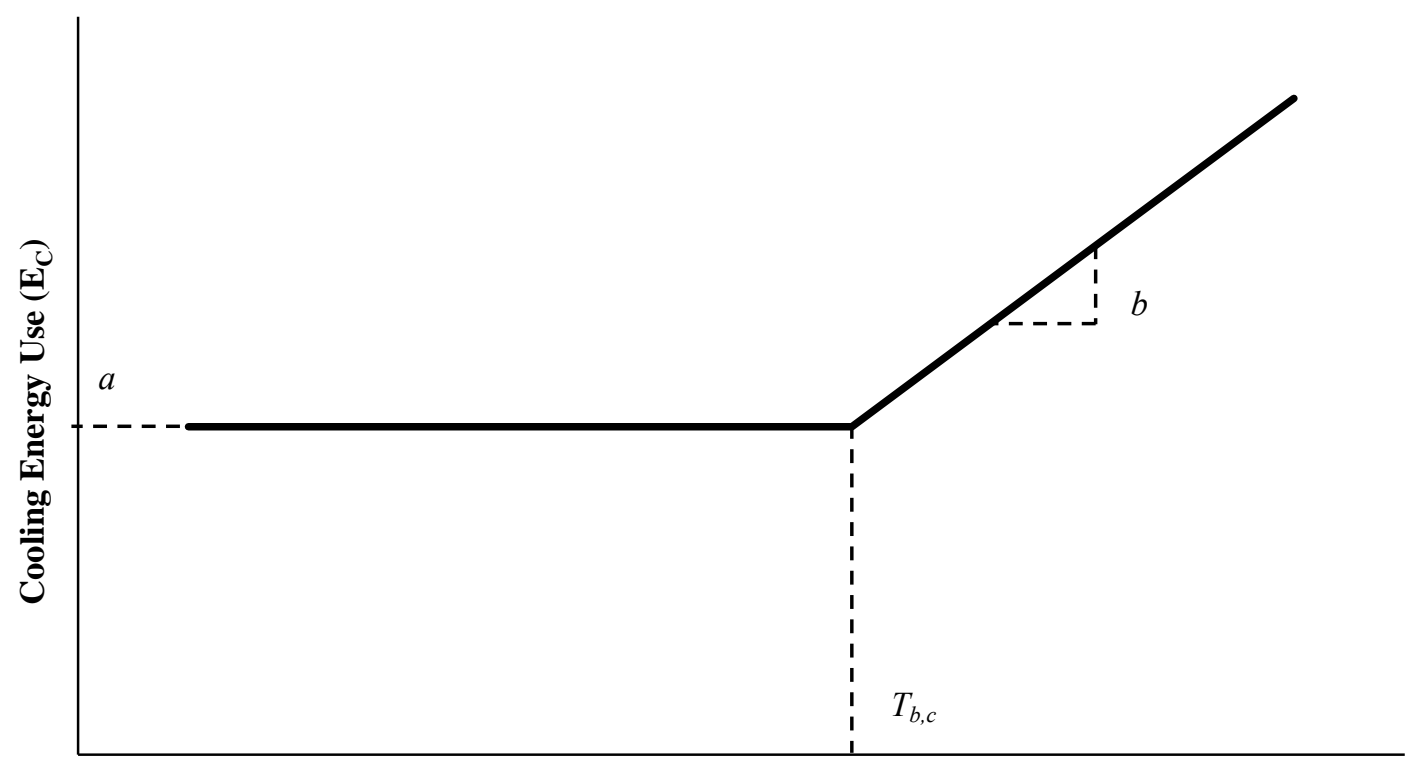

Temperature ( $\mathbf{T})$

Figure 2. Three-parameter cooling change-point model (3PC). 


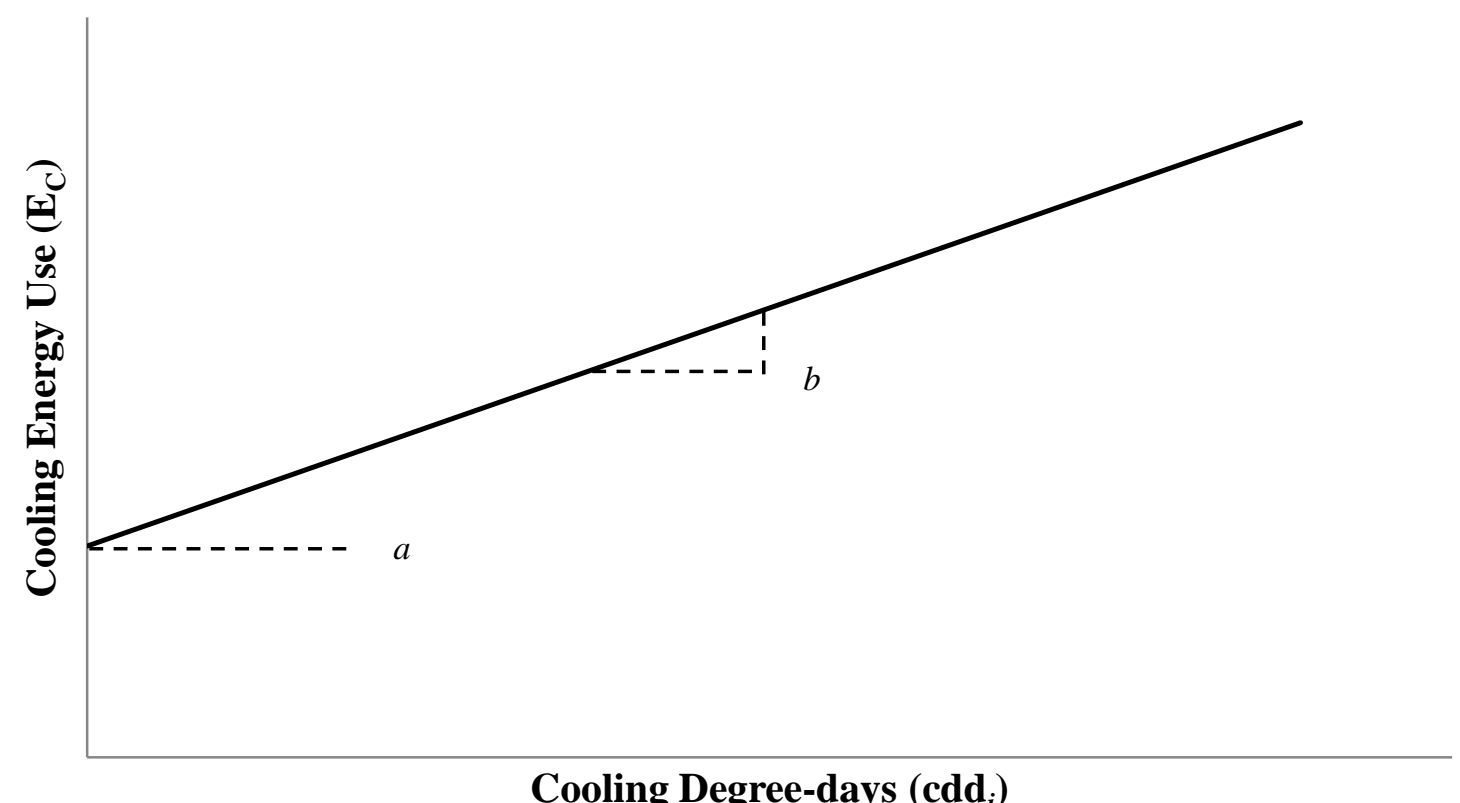

Cooling Degree-days ( cdd $\left._{i}\right)$

Figure 3. Variable-base cooling degree-day model (CDD).

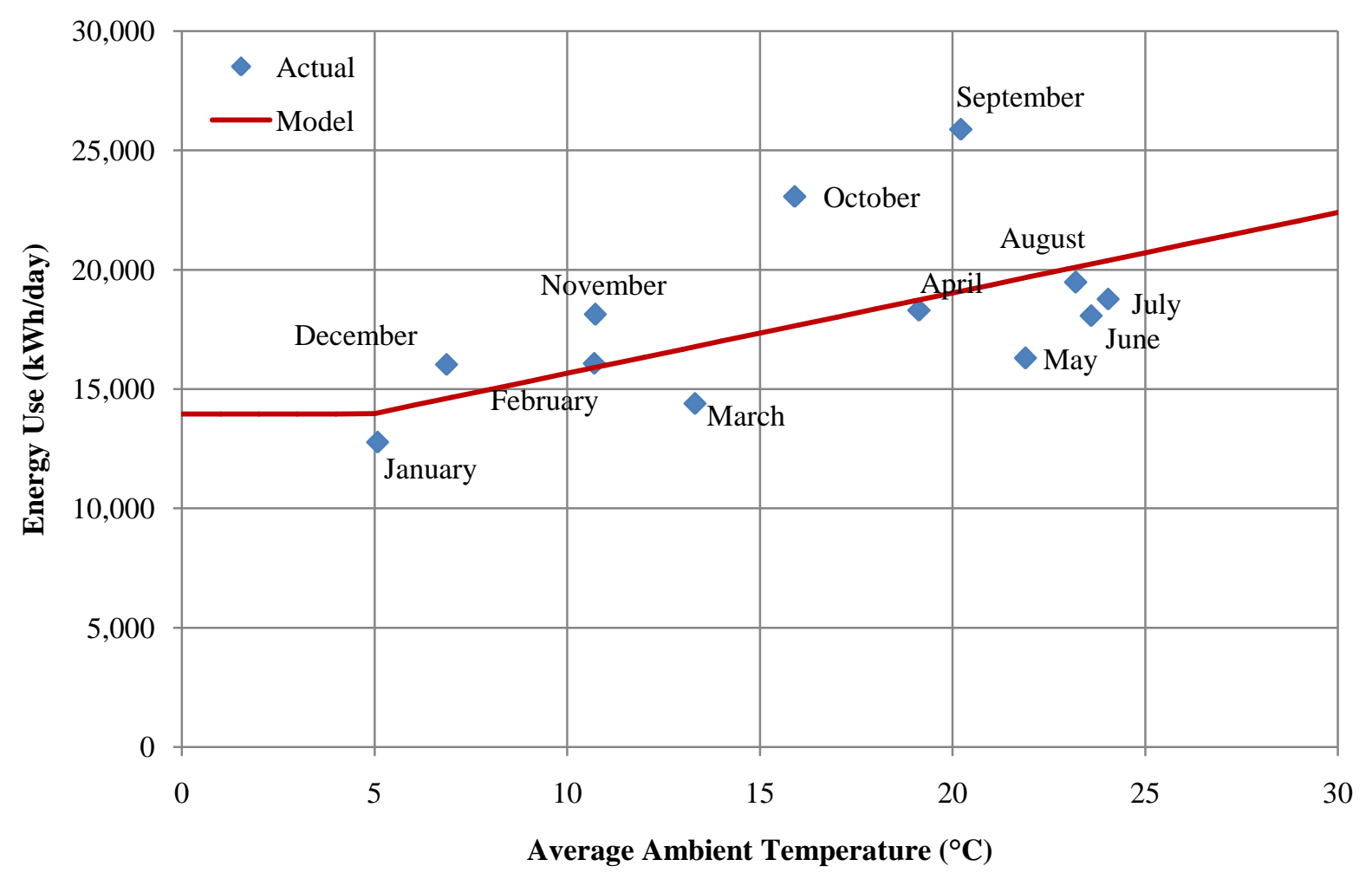

Figure 4 3PC model of monthly electrical energy use for Facility A. 


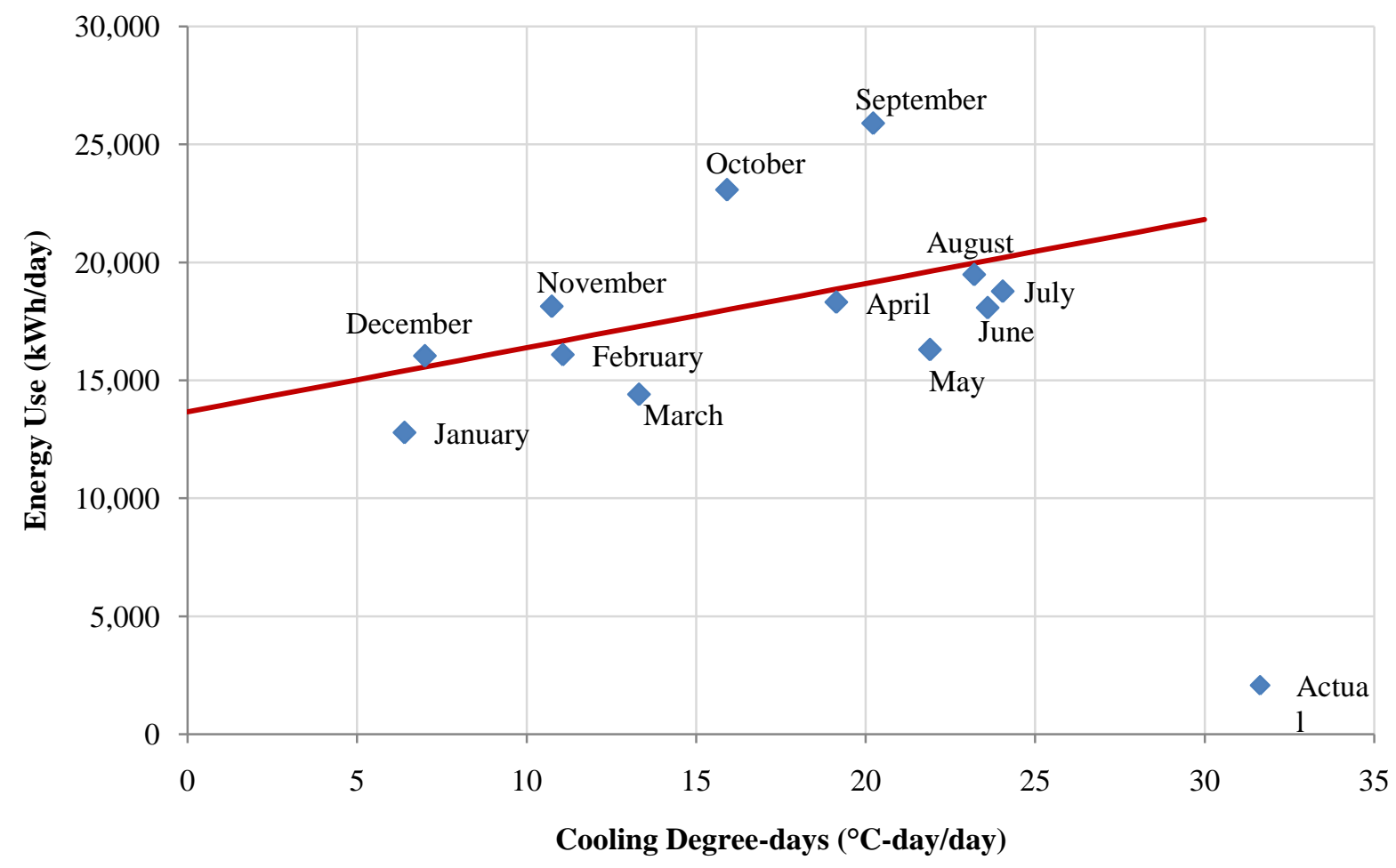

Figure 5 CDD model of monthly electrical energy use for Facility A. 


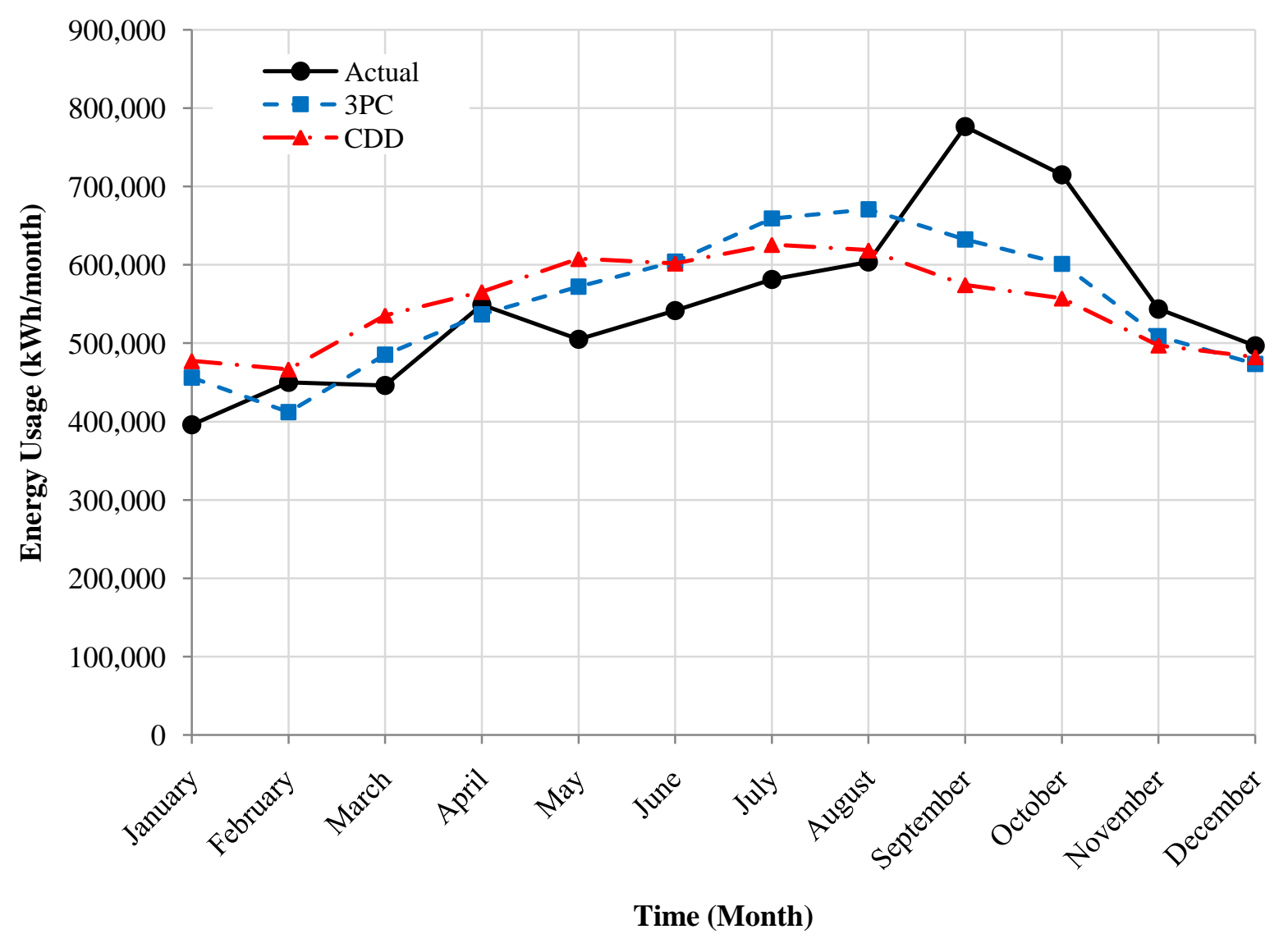

Figure 6 Actual energy usage, 3PC model energy usage, and CDD model energy usage for Facility A. 


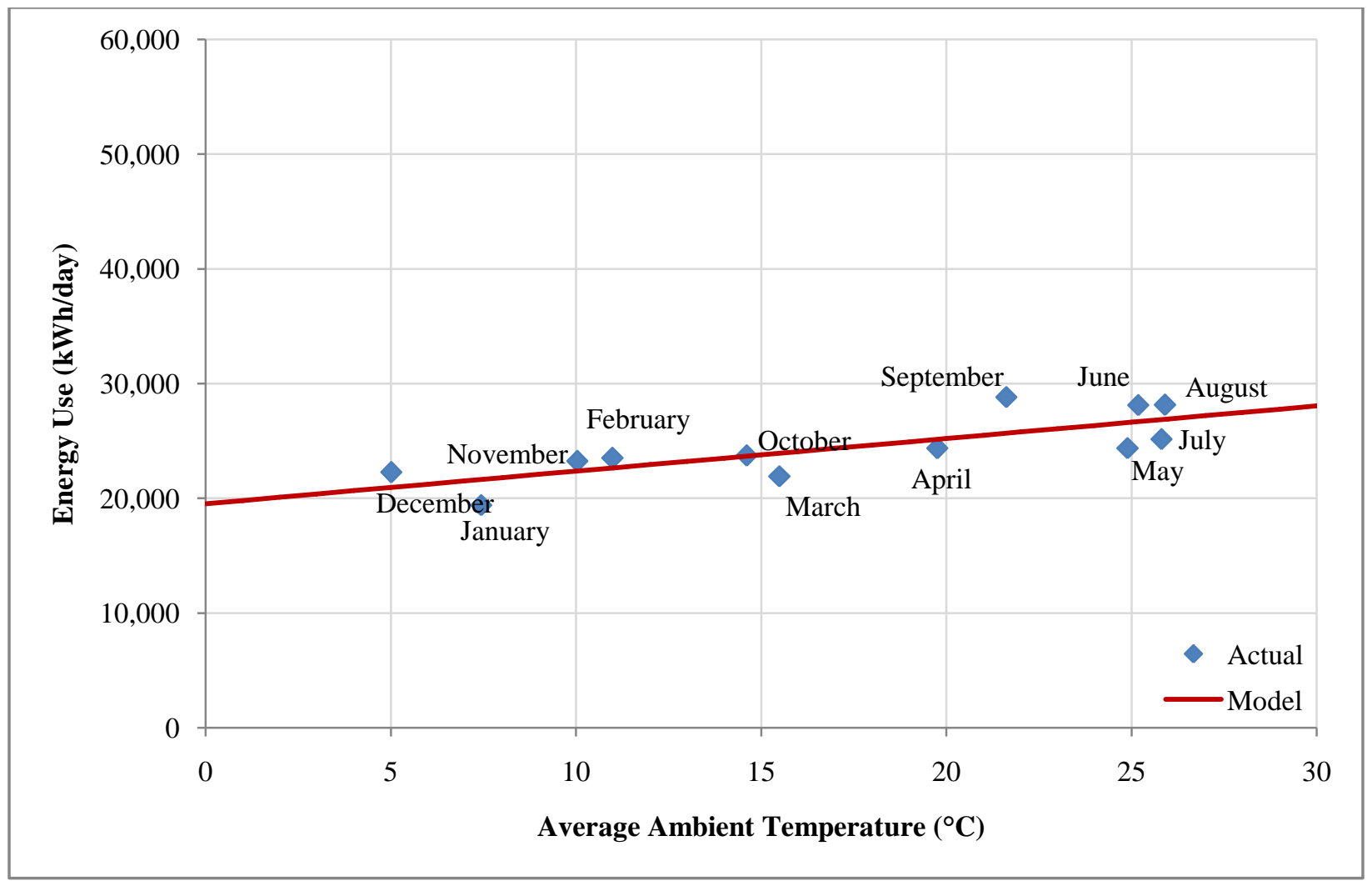

Figure 7 3PC model of monthly electrical energy use for Facility B. 


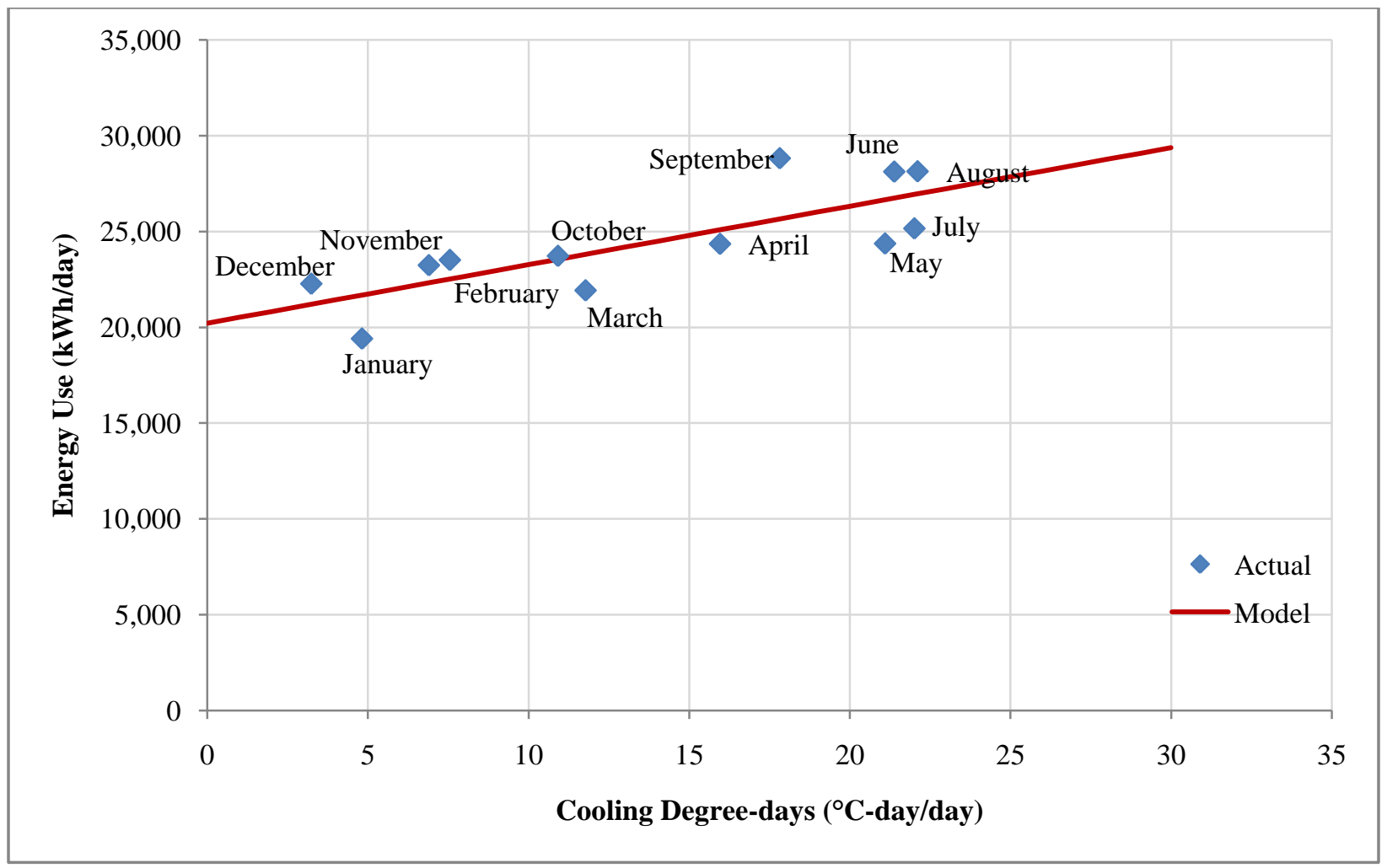

Figure 8 CDD model of monthly electrical energy use for Facility B. 


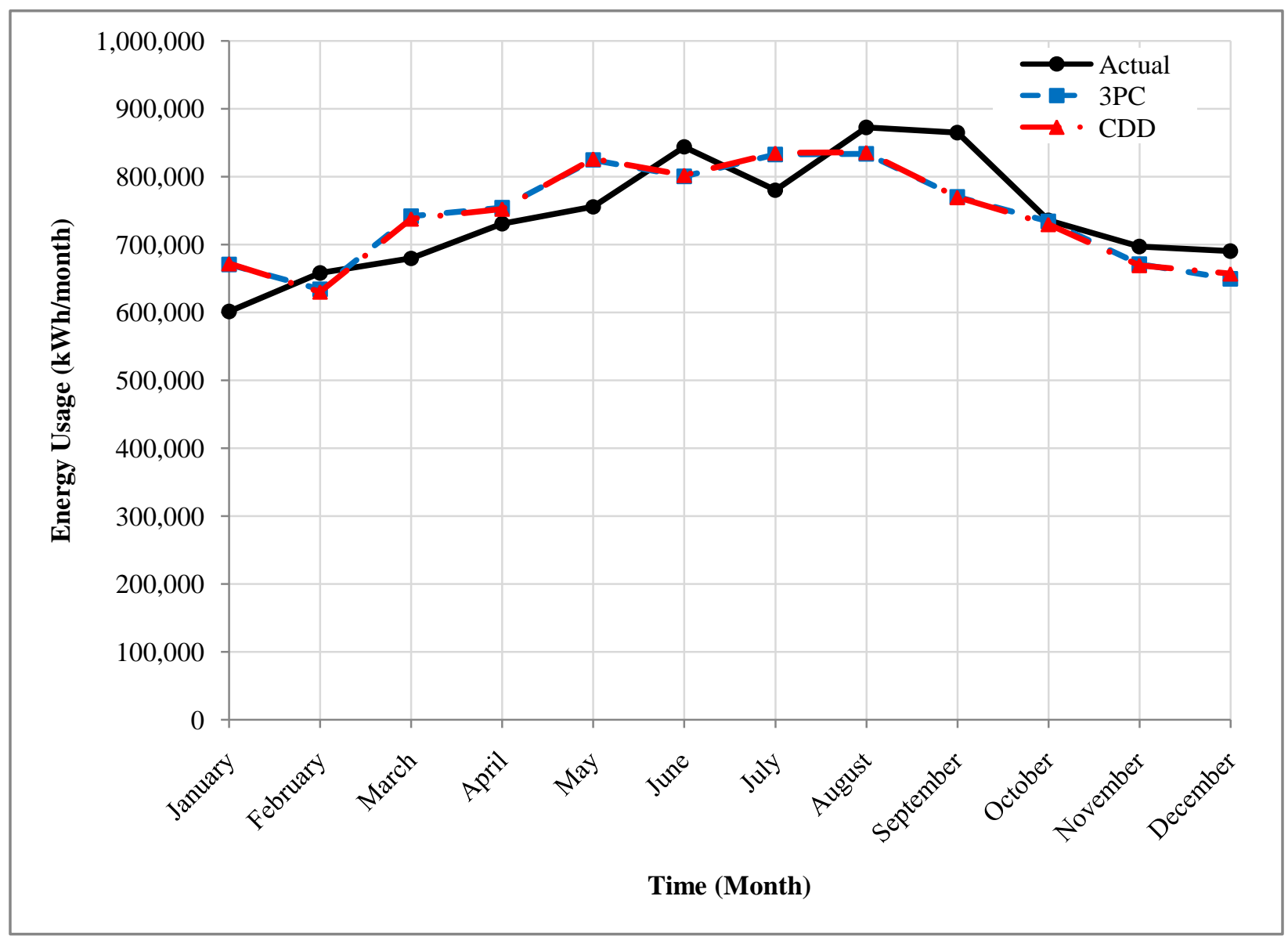

Figure 9 Actual energy usage, 3PC model energy usage, and CDD model energy usage for Facility B. 